\title{
Luanda e Maputo: inflexões suburbanísticas da cidade socialista à cidade-metrópole neoliberal
}

\author{
Luanda and Maputo: sub-urbanistic inflections from the \\ socialist city to the neoliberal metropolis city
}

Isabel Simões Raposo ${ }^{[a]}$, Silvia Jorge ${ }^{[b]}$, Silvia Viegas ${ }^{[b]}$, Vanessa Melo ${ }^{[b]}$

[a] Arquitecta-urbanista, doutora em Urbanismo pela Universidade de Paris XI, professora associada da Faculdade de Arquitectura da Universidade Técnica de Lisboa (FAUTL), Lisboa, e investigadora do Grupo de Estudos Sócio-Territoriais Urbanos e de Acção Local (GESTUAL) do Centro de Investigação em Arquitectura, Urbanismo e Design (CIAUD) da FAUTL, Lisboa - Portugal, e-mail: isaraposo52@gmail.com

[b] Arquitectas e doutorandas, investigadoras do Grupo de Estudos Sócio-Territoriais Urbanos e de Acção Local (GESTUAL) do Centro de Investigação em Arquitectura, Urbanismo e Design (CIAUD) da Faculdade de Arquitectura da Universidade Técnica de Lisboa (FAUTL), Lisboa - Portugal, e-mails: aivlisjorge@gmail.com, silvialv.metapolis@gmail.com, vanessa.p.melo@gmail.com

\section{Resumo}

Luanda e Maputo, duas capitais africanas da lusofonia, são marcadas por crescentes desigualdades socioespaciais. Os centros urbanizados dessas urbes, traçados pela e para a sociedade colonial e onde hoje reside a maioria da população de maiores recursos, distinguem-se dos densos e extensos subúrbios habitacionais suburbanizados, onde outrora residia a sociedade colonizada e hoje se acantona a população de menores recursos. Nos primeiros anos de independência, em contexto de ideologia de inspiração socialista, economia planificada e planeamento centralizado, ambos os países visaram diminuir as desigualdades socioespaciais herdadas do colonialismo, intervindo nos subúrbios. A partir de finais da década de 80 do século XX, com o início da liberalização económica e política, que levou, em Moçambique, à descentralização (ainda emergente em Angola), surgem novos actores, indutores de diferentes modelos de cidade e de fazer cidade, diversificando-se os tipos de intervenções suburbanas. A explosão, segregação e complexidade socioespacial desses subúrbios tem-se intensificado com a adopção do modelo de cidade neoliberal, competitiva e desigual. Tomando como referência esses dois grandes períodos sociopolíticos e urbanísticos, este artigo restitui, num olhar cruzado e crítico, diferentes tipos de intervenção nos subúrbios habitacionais semiurbanizados. O seu principal objectivo é reflectir sobre a circulação de influências e os paradigmas suburbanísticos em que se inscrevem.

Palavras-chave: Cidade socialista. Cidade neoliberal. Paradigmas suburbanísticos. Luanda e Maputo. 


\section{Abstract}

Luanda and Maputo, two major Lusophone African capitals, are marked by growing socio-spatial inequalities. Their urbanized centers, traced by and to the colonial society and where today lives the population with more resources, differs from the dense and extensive residential sub-urbanized suburbs, once inhabited by the colonized society and where currently lives the lower income population. In the first years of the independence, in the context of a socialist ideology, planned economy and centralized planning, both countries aimed to diminish the socio-spatial inequalities inherited from colonialism, intervening in the suburbs. From the late eighties of the twentieth century, with the beginning of the economic and political liberalization, which led, in Mozambique, to decentralization (emerging in Angola), new actors emerging and inducing different models of city and of doing the city, diversifying the types of suburban interventions. Explosion, segregation and socio-spatial complexity of these suburbs are intensifying with the model of the neoliberal city, competitive and unequal. Taking as a reference these two big socio-political and urban periods, this paper returns, in a crossed and critical look, different types of interventions in the residential sub-urbanized suburbs. Its main objective is to reflect upon the circulation of influences and the sub-urban paradigms in which they are inscribed.

Keywords: Socialist city. Neoliberal city. Sub-urban paradigms. Luanda and Maputo.

\section{Duas capitais africanas da lusofonia: legado colonial em discussão}

Luanda e Maputo eram, à hora da independência, cidades coloniais marcadamente duais, com suas zonas urbanizadas de traçado regular destinadas aos habitantes europeus e, em seu redor, extensos e precários subúrbios, "musseques" ou "caniço", bairros sub-urbanizados, na sua maior parte autoconstruídos, que alojavam os africanos, servidores dos colonos. A articulação entre a cidade urbanizada e os subúrbios nas duas capitais era todavia bem distinta, dadas as diferentes géneses, histórias sociais e urbanas e configurações territoriais.

Luanda, a primeira cidade lusa na África subequatorial (1576), seguiu o traçado típico das fundações urbanas portuguesas, adaptado à topografia e à necessidade defensiva, com a cidade alta e baixa. Esta última estendeu-se ao longo da baía, imbricando com as habitações da população autóctone. No segundo quartel do século XX, a "cidade do asfalto" expandiu-se em quadrícula pelo planalto, seguindo uma urbanística formal e empurrando os musseques que a envolviam e preenchiam os seus interstícios, os dois tecidos interpenetrando-se. Em contrapartida, a povoação de Lourenço Marques, hoje Maputo, fundada pelos portugueses em 1781, bem adaptada ao terreno, foi elevada à cidade em 1887 e beneficiou-se logo nessa data de um plano que ditou a expansão da cidade baixa, em quadrícula, crescendo em mancha de óleo de forma contínua e compacta, galgando pelo planalto e afastando os subúrbios para uma periferia progressivamente mais longínqua.

Amaral (2005) e Martins (2005) assinalam as profundas alterações que se operaram na cidade urbanizada de Luanda, desde meados do século XX, com a industrialização e o acelerado crescimento económico, populacional e urbano: destruição do centro histórico com substituição das antigas casas portuguesas, sobradas ou térreas, por uma arquitectura moderna e internacional, com obras de referência de arquitectos portugueses da "geração africana" (FERNANDES, 2002), inspirados em Le Corbusier e no moderno tropical brasileiro. 0 mesmo processo de industrialização, crescimento, destruição e modernização operou-se em Maputo, dando lugar a obras notáveis de equipamentos e edifícios residenciais na "cidade de cimento". Um dos traços dessa transformação nas duas cidades foi a verticalização, a

\footnotetext{
1 "Musseque" designa, em língua local, kimbundu, a terra vermelha das zonas do planalto para onde foram remetidos, com o crescimento da cidade urbanizada ou "cidade do asfalto", os bairros africanos, de caminhos em terra e casas de materiais naturais; em Maputo, o "caniço" designa o material que nos anos 60 predominava na construção das habitações dos subúrbios, em oposição às construções em alvenaria da "cidade de cimento".
} 
qual se intensificou na última década que antecedeu a independência, reflexo da sua "captura pela globalização”, parafraseando Amaral (2005, p. 52).

Nesse mesmo período, os subúrbios de ambas as cidades estenderam-se, observando-se lenta suburbanização e diferenciação operada pelos habitantes, com o aparecimento de casas mais urbanas, de madeira (em Luanda) e de madeira e zinco (em Maputo), de assalariados com melhor salário e assimilados, a par de uma ausência de investimento público na melhoria de infraestruturas e equipamentos. A intervenção dos arquitectos modernos nesses territórios é muito reduzida, destacando-se, nos musseques de Luanda, a obra do arquitecto e urbanista Simões de Carvalho e, sobre o "caniço" de Maputo, a publicação do arquitecto Pancho Guedes, Manual de alfabetização do vogal sem mestre, de 1968, em que defende a qualificação destes bairros e o realojamento in situ (RAPOSO, 2011).

Desde os anos 60 do século XX, em face das pressões nacionais e internacionais, a política colonial aposta na qualidade urbana e na "integração" social, preocupações incorporadas nos novos planos para Luanda (de Simões de Carvalho, desenvolvido entre 1961 e 1964) e para Lourenço Marques (do engenheiro Mário Azevedo, aprovado em 1972): o primeiro propõe a criação de Unidades de Vizinhança sobrepondo-se ao tecido do musseque, integrando tipos habitacionais e grupos sociais e étnicos (caso do Bairro Prenda); e o segundo aposta já no reconhecimento dos subúrbios, na sua infraestruturação e consolidação. 0 impacte desses planos é reduzido nos subúrbios, que só com as independências passariam a ser parte integrante das respectivas cidades e, particularmente em Maputo, objecto de intervenções de melhoramento.

Não obstante essa mudança, o investimento na sua consolidação ou urbanização é hoje muito inferior ao realizado nas zonas urbanizadas, enquanto seu aumento populacional se continua a processar mais aceleradamente e seus problemas materiais são muito mais complexos. A situação é particularmente grave em Luanda, que aloja hoje cerca dez vezes mais população que em 1970, acolhendo área suburbana equivalente a cerca de $80 \%$ do total (estimativas locais), enquanto a população de Maputo, no mesmo período, quase quadruplicou, estimando-se que $70 \%$ se alojem nos subúrbios (UN-HABITAT, 2008).
Quadro 1 - Crescimento de Luanda e Maputo entre 1970 e 2010 (censos e estimativas)

\begin{tabular}{ccccc}
\hline & 1970 & M-1980 | L-1983 & M-1997 | L-2000 & 2010 \\
\hline Luanda & 480.613 & 923.842 & 3.276 .991 & $4.772 .000^{*}$ \\
Maputo & 378.348 & 539.394 & 966.837 & $1.655 .000^{*}$ \\
\hline
\end{tabular}

Fonte: Dados disponíveis em LOPES et al., 2007; *UN-HABITAT, 2010.

A dualidade entre a cidade urbanizada e os seus subúrbios intensificou-se no último quartel, com a proliferação de grandes projectos urbanos, infraestruturais e imobiliários na cidade urbanizada e o esquecimento dos subúrbios, configurando a cidade neoliberal (RAPOSO, 2007) (ver Figura 1 A a J). Ao mesmo tempo, acentuaram-se as diferenças entre e no interior de cada bairro suburbanizado (RAPOSO; SALVADOR, 2007), apelando a novos estudos sobre a sua génese e metamorfose e sobre novas formas de pensar e intervir nessas extensões suburbanas, questionando-se o que fazer (FORJAZ, 2005).

Este texto actualiza uma investigação concluída sobre as duas cidades (OPPENHEIMER; RAPOSO, 2007; RAPOSO, 2007) com pesquisas em curso (JORGE; MELO, 2012; MELO, 2012; VIEGAS, 2012) que têm como denominador comum compreender as actuais políticas e práticas de intervenção nos subúrbios, tendo como pano de fundo as transformações urbanas ocorridas desde as independências. Entendendo o espaço como produto do social e do capital, na linha de Lefebvre (1974) e Harvey (2001), distinguem-se dois grandes momentos de ruptura, sociopolíticos e urbanísticos, que marcam essas cidades desde 1975: 10 anos de transição visando à criação de uma cidade socialista africana e 25 anos de construção de uma cidade neoliberal que se consolida no novo milénio.

Os três pontos seguintes - utopia socialista, construção da cidade neoliberal e paradigmas recentes de intervenção suburbanísticos - procuram responder às seguintes questões: quais influências e configurações favoreceram ou dificultaram a diminuição da dualidade urbana? Quais as que no período neoliberal têm visado e agudizado essa dualidade ou, pelo contrário, procuram atenuá-la? Quais os paradigmas suburbanísticos subjacentes a novas formas emancipadoras de pensar e intervir nestes territórios? 

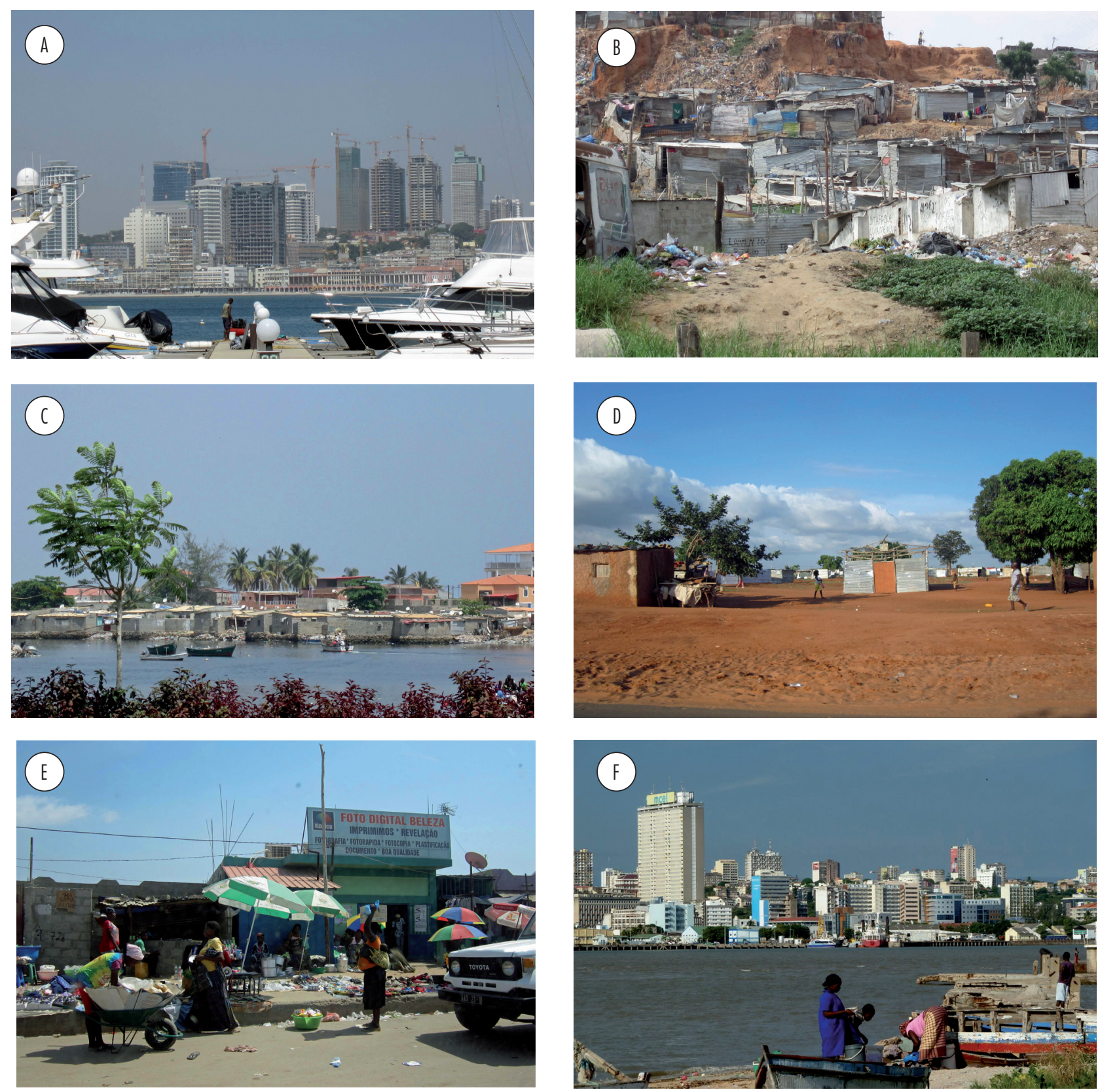

(Continua)

Figura 1 - Centros urbanizados e subúrbios de Luanda e Maputo

Legendas: 1A | Centro urbanizado de Luanda. Fonte: Sílvia Viegas, 2012; 1B | Subúrbios mais centrais de Luanda. Fonte: Sílvia Viegas, 2012; 1C | Subúrbios mais centrais de Luanda. Fonte: Silvia Viegas, 2012; 1D | Subúrbios mais periféricos de Luanda. Fonte: Silvia Viegas, 2012; IE | Subúrbios mais periféricos de Luanda. Fonte: Silvia Viegas, 2012; IF | Centro urbanizado de Maputo. Fonte: Rodrigo Rosário, 2011.

\section{Utopia socialista}

A independência dos dois países, conquistada na sequência de uma década de luta armada conduzida por movimentos progressivamente politizados, materializou-se com jovens governos de partido único - o Movimento Popular de Libertação de Angola (MPLA) e a Frente de Libertação de Moçambique (Frelimo) - perfilhando um discurso marxista-leninista e uma ideologia de inspiração socialista. Optando por uma economia planificada e centralizada, com apoio sobretudo dos países do Leste europeu e de Cuba, essas novas governações operaram mudança 

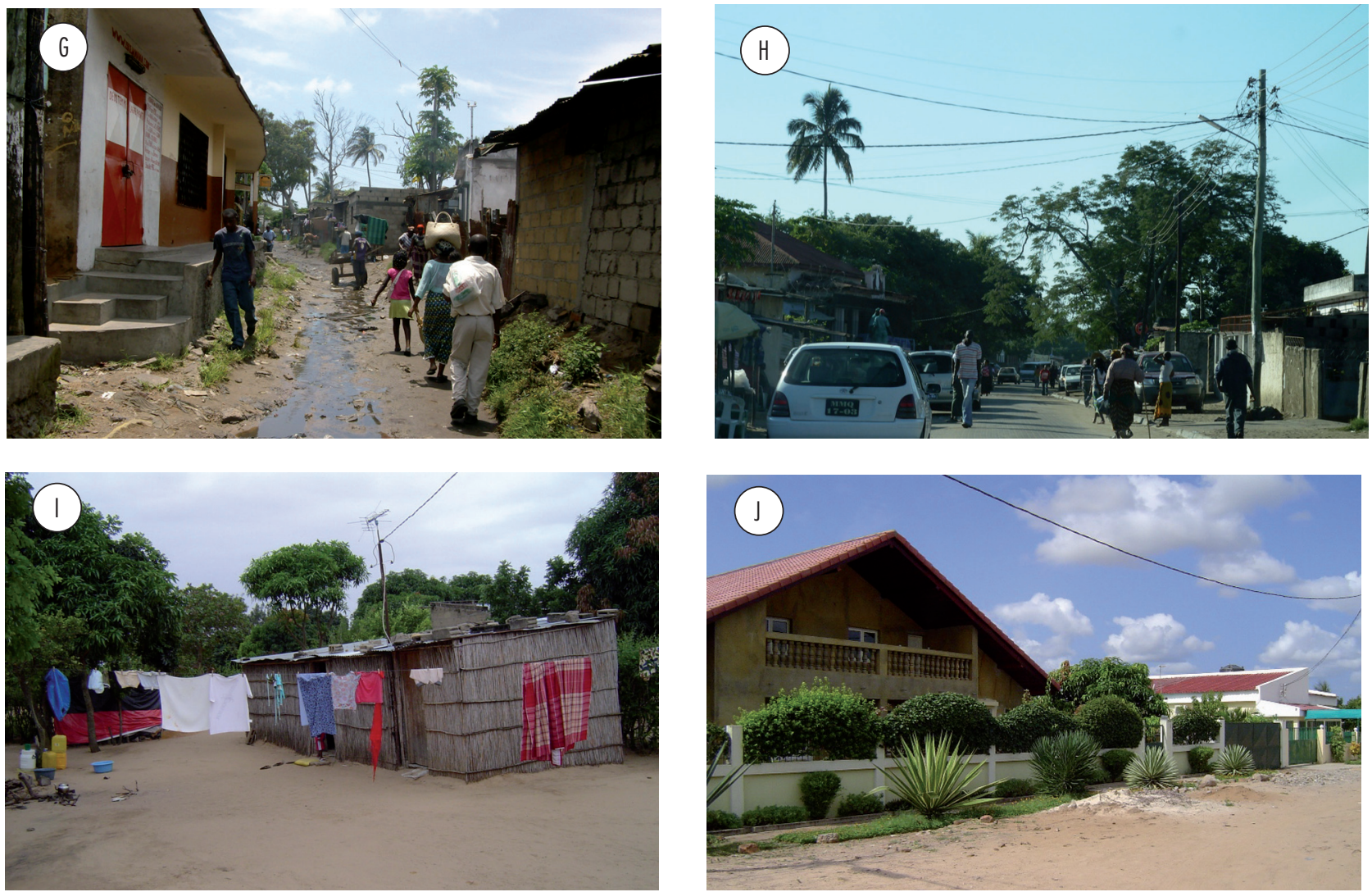

(Conclusão)

Figura 1 - Centros urbanizados e subúrbios de Luanda e Maputo

Legendas: $1 \mathrm{G} \mathrm{|} \mathrm{Subúrbios} \mathrm{mais} \mathrm{centrais} \mathrm{de} \mathrm{Maputo.} \mathrm{Fonte:} \mathrm{Silvia} \mathrm{Jorge,} \mathrm{2011;} \mathrm{1H} \mathrm{|} \mathrm{Subúrbios} \mathrm{mais} \mathrm{centrais} \mathrm{de} \mathrm{Maputo.} \mathrm{Fonte:} \mathrm{Isabel} \mathrm{Raposo,} \mathrm{2011;} 11$ | Subúrbios mais periféricos de Maputo. Fonte: Vanessa Melo, 2011; 1J | Subúrbios mais periféricos de Maputo. Fonte: Sílvia Viegas, 2011.

abrupta nas políticas e práticas urbanas, tendo como princípio orientador a redução da dualidade urbana. Como principais medidas e acções tomadas com esse objectivo, destacam-se:

- A nacionalização da terra e dos prédios de rendimentos (1976 em Angola, e respectivamente em 1975 e 1976, em Moçambique) - em Moçambique, foram criados novos critérios de rendas (1976) em função do rendimento e da dimensão do agregado familiar que significaram a subvenção da habitação.

- A nacionalização da educação e da saúde em Moçambique em 1975, estendendo a todos os bairros a rede escolar de nível primário.

- A interrupção da verticalização como símbolo da rejeição do modelo de cidade capitalista, facilitada pela fuga dos colonos e pela crise económica - alguns prédios nacionalizados, nalguns casos ainda em construção, foram ocupados pela população dos subúrbios, como a paradigmática torre de 22 pisos na zona do mercado Kinaxixe, em Luanda.

- A inclusão dos subúrbios na divisão administrativa da cidade (1979 em Maputo e 1980 em Luanda).

- A criação de novas estruturas da administração pública com responsabilidade de intervenção nos subúrbios - em Luanda, o Ministério de Obras Públicas e Habitação deu continuidade ao trabalho desenvolvido em 1974 pelo Gabinete de Urbanização e Habitação, de inventariação e reordenamento dos musseques, na senda da intervenção integrada no Bairro Golfe pelo arquitecto português Troufa Real. Posteriormente, a Direcção Nacional de Planificação Física (DNPF) recebeu forte apoio cubano, que investiu sobretudo na construção de edifícios de habitação colectiva, na pré-fabricação e importação 
de materiais de construção. Em Maputo, a Direcção Nacional de Habitação (DNH), convertida em 1983 em Instituto Nacional de Planeamento Físico (INPF), sob a direcção democrática do arquitecto moçambicano José Forjaz, atraiu uma miríade de cooperantes de várias proveniências (portugueses, europeus, do Leste europeu, da América Latina e do Norte), trouxe figuras como Friedmann (1978) e estimulou a procura de soluções inovadoras e emancipadoras; ao mesmo tempo, lançou um plano de formação de quadros de planificação física - integrando alunos formados em Cuba - que constituiu a base da criação dos serviços provinciais e influenciou a criação da Faculdade de Arquitectura e Planificação Física (FAPF) da Universidade Eduardo Mondlane, com apoio da cooperação italiana.

- O afastamento dos planos directores elaborados pela administração colonial deu lugar a novos planos preocupados com o desenvolvimento global da cidade, incluindo os subúrbios, que, todavia, não chegaram a ser aprovados, sendo ultrapassados pelas grandes transformações de que as duas capitais são palco - em Luanda, em 1979, foi elaborado um esquema preliminar de Plano Director, na DNPF, com assistência cubana. Em Maputo, em 1985, foi elaborado um Plano de Estrutura, no INPF, por cooperantes europeus, com ampla discussão interinstitucional.

- A defesa da autoconstrução - em Luanda, foi criada uma Lei sobre autoconstrução, em 1982, que visava à "demarcação de parcelas e áreas para serviços sociais e o fornecimento de materiais de construção subsidiados", mas a procura excedeu a capacidade de resposta do governo local (DEVELOPMENT WORKSHOP, 2005, p. 72). Em Maputo, a autoconstrução é defendida no documento da 1ํ Reunião Nacional sobre Cidades e Bairros Comunais (1979), tendo sido entregues, entre 1975 e 1985, cerca de 14.400 talhões (para Maputo e Matola) (OPPENHEIMER; RAPOSO, 2002). Face ao afluxo à cidade, esse número foi insuficiente, tal como o subsídio de materiais de construção e a disponibilização de terreno infraestruturado, "sites and services".

- A instalação de infraestruturas e equipamentos (fontanário, escola primária e centro de saúde) nos bairros suburbanos, especificamente em Maputo, no quadro do Programa dos Bairros Comunais.

- E, em remate, pelo seu carácter inovador, o reordenamento dos bairros de Maxaquene e Polana Caniço, em Maputo, entre 1976 e 1978, por meio de um processo participado e flexível, da iniciativa da DNH, com o apoio das Nações Unidas e coordenação de um arquitecto sueco.

Muitas dessas medidas foram favoráveis aos citadinos, contribuindo para o aumento da atracção exercida pelas duas capitais. Essa vontade transformadora, inscrita no objectivo de criar uma sociedade e uma cidade socialistas, mais justas, particularmente presente nos discursos dos primeiros anos de independência, foi confrontada com inúmeros obstáculos, destacando-se os violentos e prolongados conflitos armados deflagrados logo a seguir à declaração das independências (em 1975 em Angola, e em 1977, em Moçambique). A esses se adicionam: a fuga dos colonos, levando consigo muitos quadros técnicos; as graves crises económicas nacionais; a dificuldade de implementação de algumas das políticas adoptadas, como a incapacidade do Estado proceder à manutenção do parque imobiliário nacionalizado em degradação; a desestruturação e reestruturação do aparelho administrativo; a falta de informação, de quadros nacionais e de recursos financeiros; a burocracia paralisadora; as próprias "calamidades naturais" (secas e cheias) e o imparável afluxo de rurais, adensando os problemas dos subúrbios. Nesse contexto, as duas cidades viram esbatida a dualidade colonial com a deterioração de imóveis, espaço público e infraestruturas das zonas urbanizadas, mas os subúrbios cresciam exponencialmente.

Algumas medidas então tomadas para conter a expansão urbana revelaram-se excessivamente burocratas e contraproducentes, como a "guia de marcha" em Moçambique, mas também fortemente repressivas, em particular sobre a população dos subúrbios, como foi, também em Moçambique, a Operação 
Produção (1983), assente na evacuação forçada para o campo dos chamados "improdutivos"2. Essa medida teve forte impacto na desagregação e precarização familiar, marcando "o princípio do fim da hegemonia da ideologia socialista do partido/Estado" (OPPENHEIMER; RAPOSO, 2002, p. 17).

\section{Construção da cidade metrópole neoliberal}

\section{Mudança económica e política}

0 enfraquecimento e o posterior desmoronamento do bloco socialista (marcado pela queda do Muro de Berlim em 1989), com o qual se alinhavam Angola e Moçambique, tiveram implicações claras nas mudanças profundas operadas, desde meados da década de 80, nesses dois países, pressionados pelas organizações internacionais e a braços com graves crises internas: a abertura à economia de mercado e a um sistema multipartidário. No início da década de 90, ao mesmo tempo em que na vizinha África do Sul ensaia o desmantelamento do regime do apartheid, assiste-se, em 1991, em Angola, e, em 1992, em Moçambique, ao fim de mais de dez anos de violentas guerras civis, desencadeadas por movimentos com forte apoio externo (da África do Sul e dos Estados Unidos) - embora no primeiro país o conflito volte a eclodir drasticamente em 1992 e só termine dez anos mais tarde.

No âmbito económico, ambos os países seguiram os passos de um capitalismo neoliberal, abrindo as portas à livre circulação de capitais, à privatização crescente dos vários sectores económicos e sociais e à retracção da intervenção do Estado e da sua função reguladora. Essas medidas, agravadas em situação de guerra civil, embora tenham ditado algum crescimento económico, provocaram, por um lado, o desemprego e o aumento do sector informal da economia e, por outro, a concentração da rique$\mathrm{za}$, agravando as desigualdades de rendimentos, a segregação socioespacial, a precarização das condições de vida e os níveis de pobreza (OPPENHEIMER; RAPOSO, 2002, 2007).
Angola, graças a sua relativa autonomia financeira, resultante do controle da exploração do petróleo, pôde contrair empréstimos em bancos internacionais (CROESE, 2011) e resistir à implementação de um programa de ajustamento estrutural mais rígido submetido às orientações das organizações de Bretton Woods. Todavia, em virtude do prolongamento e da intensificação da guerra, na década de 90, Luanda beneficiou-se de pouco investimento nas áreas urbanizadas e as suburbanizadas, onde se adensava a população fugida das áreas de conflito, estenderam-se e degradaram-se.

Moçambique, sem qualquer autonomia financeira e findo o apoio do bloco socialista, foi pressionado pelos doadores internacionais a adoptar os programas de estabilização financeira e ajustamento estrutural, seguindo à letra a cartilha do Fundo Monetário Internacional (FMI) e do Banco Mundial (BM). Em consequência e apesar do fim da guerra, da retoma da produção rural familiar, do aumento do sector informal e dos grandes projectos de investimento estrangeiro, nomeadamente produtivos, como o Corredor Maputo-Witbank, a desigualdade e a pobreza urbana agravaram-se, emergindo um processo mercantil de periferização das famílias de menores recursos, nomeadamente impelidas a deixar as áreas urbanizadas (OPPENHEIMER; RAPOSO, 2002).

No âmbito político, para além da abertura ao multipartidarismo, que os dois países concretizaram no início da década de $90^{3}$, as novas Leis das Associações criadas em 1991 (em Angola, Lei n. 14/91 e em Moçambique, Lei n. 8/91) permitiram a entrada em cena de novos actores. Nas zonas urbanizadas, os investidores privados assumiram um papel cada vez mais preponderante, com o investimento de empresas estrangeiras em grandes projectos, muitas vezes marginalizando o município ou o governo provincial da gestão desses territórios e dos benefícios económicos que propiciaram, precarizando e periferizando os pobres urbanos. Essa diferenciação entre umas e outras áreas é reforçada pela actuação do poder público, com a política de privatização dos serviços urbanos, com capital europeu e privado nacional, bem como do parque

\footnotetext{
2 Eram tidos como improdutivos urbanos "todos os que não dispunham ou que fossem interceptados sem os vários documentos de identificação então exigidos” (OPPENHEIMER; RAPOSO, 2002, p. 16).

3 O multipartidarismo foi inscrito nas novas constituições dos dois países, em 1989 em Angola e em 1990 em Moçambique, e as eleições gerais decorrem em 1992 e em 1994.
} 
imobiliário, gerando processos de gentrification dos bairros centrais. Em contrapartida, nos subúrbios, são sobretudo as organizações cívicas, as organizações não governamentais (ONG) nacionais e internacionais, as congregações religiosas e as organizações comunitárias de base, que intervêm no desenvolvimento suburbano, amiúde, em articulação com as agências internacionais, inicialmente sem ou com pouca articulação com o poder público local. As suas acções, geralmente de carácter pontual e paliativo (RAPOSO; RIBEIRO, 2007), são insuficientes em face de uma situação cada vez mais extensa e complexa.

0 processo de descentralização e municipalização, que se enquadra no conjunto de reformas económicas e administrativas do pacote neoliberal, é apresentado pelos doadores internacionais como condição para a ajuda externa aos subúrbios. Em Angola, dado o forte poder central e presidencial, o processo não foi implementado, apesar da reivindicação do Governo Provincial de Luanda (GPL) (1997) por maior descentralização. As administrações municipais permaneceram sem qualquer autonomia, situação propícia a práticas burocráticas e autoritárias, configurando, como refere Fauré (2011), uma municipalização sem descentralização. 0 actual Instituto de Planeamento e Gestão Urbana de Luanda (IPGUL), tutelado pelo GPL, visa a promover a descentralização administrativa do Estado e coordenar os vários planos de ordenamento do território, no quadro da profunda metamorfose de que Luanda é palco. Todavia, o responsável pelos projectos estratégicos no território continuou a ser o Gabinete de Reconstrução Nacional (GRN), com financiamento chinês e directamente dependente do presidente Eduardo dos Santos. Com a sua recente extinção (2011), os projectos estratégicos de obras públicas passaram a ser geridos pelo novo Gabinete de Obras Especiais (GOE), igualmente dependente do presidente ${ }^{4}$, e os projectos imobiliários pela empresa Sonangol Imobiliária.

Em Moçambique, mais pressionado pelas agências internacionais, em especial pelo BM, o processo de descentralização iniciou a seguir às eleições multipartidárias, presidenciais e parlamentares, com a aprovação da Lei dos Municípios em 1994, e da Lei das Autarquias, em 1997, que conduziu à criação da autarquia de Maputo e à realização das primeiras eleições autárquicas, em julho de 1998. Assistiu-se nesta capital a um processo de descentralização célere, apesar das fragilidades que persistiram nos âmbitos financeiro, técnico e democrático (RAPOSO, 2007).

No novo milénio, o modelo de economia neoliberal consolida-se, fortalecido em Angola com o fim da guerra, assistindo-se à crescente desregulação dos mercados e à promoção do crescimento económico numa lógica competitiva e desigual, através da captação directa de grandes investimentos, sobretudo de grandes operadores internacionais, em grande parte para o sector de infraestruturas e imobiliário, direccionado quase exclusivamente para as classes média e alta. A proveniência dos actores intervenientes diversifica-se (sublinhe-se o papel crescente de países emergentes como a China e o Brasil) e suas intervenções multiplicam-se, disseminando novos modelos urbanos.

\section{Instrumentos urbanísticos e jurídicos}

As mudanças políticas e económicas ocorridas vão ter repercussões, quer ao nível das opções estratégicas quer dos autores dos planos, os quais também colaboram na construção da cidade neoliberal.

Em Luanda, nos anos 90, em situação de guerra prolongada, sem descentralização e com um governo provincial submetido ao poder central e presidencial, é elaborado, top-down, o Plano de Uso do Solo e Gestão do Crescimento Urbano de Luanda, por uma consultora internacional, Dar-Al-Handasah, com financiamento do BM, coordenação do GPL e do Ministério de Planeamento, aprovado em 2000 (Resolução n. 27/2000 do Conselho de Ministros). Como exemplo do forte poder presidencial, refira-se a marginalização da Carta Estratégica para Luanda, elaborada em 2001 pelo GPL com apoio de uma empresa portuguesa, que entrou em contradição com a estratégia desenvolvida pelo GOE, levando ao cancelamento do protocolo com a equipa portuguesa e à demissão do governador, defensor da descentralização (RAPOSO, 2007). Com sinal contrário, anos

\footnotetext{
4 CASA CIVIL DO PRESIDENTE DA REPÚBLICA DA ANGOLA. Diário da República: I SÉRIE — N. 150, de 8 de agosto de 2011. Disponível
} em < http://www.casacivilpr.ao/pt/documentos/25a62162e1454a020 eb912668b288214b5725e23.pdf >. Acesso em out. 2012. 
depois, outra empresa portuguesa (A1V2) financiada pelo governo central de Angola elaborou os termos de referência (2009) do concurso internacional para elaboração do novo Plano Geral Metropolitano de Luanda, que engloba a província vizinha do Bengo e visa a colocar a região metropolitana no contexto das grandes metrópoles mundiais.

Na última década, com a paz e a euforia económica, uma panóplia de outros planos parcelares para Luanda têm sido desenhados por várias empresas internacionais e consultores estrangeiros visando a sua renovação e modernização, assentes em despejos e na relocalização dos mais pobres em zonas periféricas. É exemplo o Plano Director para a Reconversão Urbana do Cazenga, Sambizanga e Rangel, "Luanda Norte", promovido em 2012 pelo Gabinete Técnico de Reconversão Urbana do Cazenga e Sambizanga e desenvolvido por uma empresa de Singapura com uma empresa portuguesa parceira, apostando na renovação, na criação de grandes parques e na relocalização dos assentamentos autoconstruídos ${ }^{5}$. 0 plano foi discutido pela classe profissional e académica, que levantou questões sobre o realojamento, a qualificação dos serviços básicos e a criação de postos de trabalho. Esses novos planos, elaborados por equipas estrangeiras, em geral sem ou com insuficiente diagnóstico local, nem debate alargado, assentam numa lógica de competitividade internacional, reprodutora do modelo da cidade neoliberal, sem preocupação de coesão social. Todavia, nem sempre são aprovados e, quando o são, sua implementação tem sido pontual e submetida à pressão dos grandes interesses do capital imobiliário.

Em face dos problemas habitacionais inerentes ao agravamento das desigualdades socioespaciais, o governo respondeu nas eleições legislativas de 2008, com o compromisso de construir um milhão de casas em quatro anos, por meio do programa Meu Sonho, Minha Casa, na senda do mediático programa brasileiro Minha Casa, Minha Vida. Contudo, alguns projectos que o concretizam, nomeadamente, a paradigmática cidade-satélite do Kilamba, em Luanda, construída em parceria com a China, têm colocado as habitações no mercado a um preço inacessível à maioria da população.
Em Moçambique, as agências internacionais continuam a ter forte influência na definição de estratégias, políticas, programas e planos urbanos, mas em interacção com a sociedade civil. Na capital, em 1999, é elaborado o Plano de Estrutura da Área Metropolitana de Maputo, financiado pelo BM no quadro do Programa de Reforma dos Órgãos Locais e elaborado por duas empresas multinacionais (Arcadis Euroconsult e JTK Associates), incluindo técnicos brasileiros, numa perspectiva top-down, sem envolver os actores socioeconómicos e as organizações cívicas. Contrariamente ao plano de Luanda de 1997, "a sua discussão gerou grande polémica na Assembleia Municipal de Maputo, que não permitiu a sua aprovação, sinal da existência de uma sociedade civil combativa" (RAPOSO, 2007, p. 229).

Os novos planos municipais foram elaborados por entidades moçambicanas e aprovados pelo Conselho Municipal. É o caso do actual Plano de Estrutura Urbana de Maputo (2008), elaborado pelo Centro de Estudos e Desenvolvimento do Habitat (CEDH) da UEM, com discussão pública alargada à sociedade civil organizada. 0 plano lançou várias acções estruturantes que estão a ser implementadas: uma nova centralidade na periferia (Zimpeto), a ponte Maputo-Catembe e a $2^{\text {a }}$ Circular. É também o caso dos Planos Parciais de Urbanização de alguns bairros suburbanos a norte do município (2010), que reconhecem o tecido existente autoproduzido como espaço a consolidar, permitindo ao Conselho Municipal iniciar a preparação da sua regularização massiva. Esses planos enquadram-se no Programa de Desenvolvimento Municipal, ProMaputo (20072016), financiado pelo BM e que visa ao fortalecimento institucional do município ao nível organizativo, técnico e financeiro, à melhoria da cobertura e qualidade dos serviços municipais em toda a cidade, à maior atenção às políticas e acções municipais para as periferias. É o caso da Estratégia Municipal de Intervenções em Assentamentos Informais, do Quadro da Política de Reassentamento, ou, em âmbito operacional, da recuperação da Av. Julius Nyerere, embora esta faça tábua rasa do tecido autoproduzido envolvente, beneficiando a cidade urbanizada. Importa ainda destacar uma iniciativa

\footnotetext{
5 OPERA PROJECTS. Joint Research Between Opera / Design Matters And Piep. Disponível em: <http://www.opera-projects. com/newsletter $/$ newsletter.aspx?lang=ing\&id_object=2552\&id_class=227\&id_user=2529\&msgPersonalizacao $=$ Dear $>$. Acesso em: out. 2012.
} 
da última década direccionada para os subúrbios, o Melhoramento dos Assentamento Informais, financiado pelo Cities Without Slums, programa das Nações Unidas promovido pela Direcção Nacional de Planeamento e Ordenamento Territorial, herdeira do INPF, e realizado por uma equipa moçambicana do CEDH, coordenada por José Forjaz (2006).

A produção dos novos planos enquadra-se, do ponto de vista jurídico, num recente conjunto de diplomas legais fortemente influenciado pela legislação portuguesa: em Angola, a Lei do Ordenamento do Território e do Urbanismo (Lei n. 3/2004); e em Moçambique, a Lei do Ordenamento do Território (Lei n. 19/2007). Destaca-se ainda, de carácter mais endógeno, a publicação da Lei de Terras (em Angola, Lei n. 9/2004, e em Moçambique, o Decreto-Lei n. 19/1997), segundo a qual a terra permanece propriedade do Estado. Embora se preveja a atribuição de títulos de ocupação, o seu impacte junto à população de menores recursos é escasso, contribuindo para o crescimento do mercado informal de terrenos e habitações, bem como para a insegurança de posse de terra. Em Angola, esse cenário é particularmente expressivo, em face da excessiva centralização de um Estado presidencialista que favorece o investimento imobiliário em detrimento das necessidades socioterritoriais.

Reconfiguram-se, nesse cenário, cidades acentuadamente duais, mais fortemente em Luanda, expostas aos fluxos globais do capital e a um processo acelerado de transformação urbana direccionada para as classes média e alta, desenhando grandes obras de infraestruturas, rodovias, equipamentos e conjuntos residenciais, condomínios fechados de moradias e em altura, a par da verticalização das áreas centrais. Essa metamorfose assenta na tábua rasa, progressiva ou brusca, dos tecidos autoproduzidos existentes, os quais também se diferenciam, expandem e periferizam.

\section{Paradigmas recentes de intervenção suburbanística}

Ao nível do território, a diversidade de poderes, interesses, racionalidades e estratégias dos vários actores traduz-se em diferentes paradigmas de intervenção suburbanísticos, situados entre duas perspectivas contraditórias: as de contorno neoliberal, ligadas a um complexo sistema global, que reproduzem o modelo urbano internacional, formatado segundo os princípios excludentes da rentabilidade financeira, visando a estender a cidade urbanizada à custa dos territórios autoproduzidos e que reforçam a segregação socioespacial; e as de carácter emancipatório, que visam a atenuação das desigualdades socioespaciais na procura de uma cidade mais inclusiva, assente no reconhecimento da cidade autoproduzida e na inclusão dos seus habitantes como actores da sua transformação (HARVEY, 2008).

A perspectiva neoliberal, claramente presente nas intervenções de renovação e de expansão urbana mercantilizada, tem vindo a conquistar mais importância em ambas as cidades, sobretudo em áreas sujeitas a maior interesse e pressão imobiliária pela sua localização estratégica. Mais prementes em Luanda do que em Maputo, essas acções são movidas sobretudo pelos investidores privados e contam com a iniciativa, o incentivo ou a conivência do Estado. Como refere Valença (2006, p. 185), parafraseando Harvey, "o capital constrói, destrói e reconstrói a cidade à sua semelhança”.

\section{Renovação urbana}

Ao nível da renovação distinguem-se grandes e pequenas intervenções, conduzidas pelo Estado e grandes promotores, ou por pequenos investidores privados. Em Luanda, dominam as grandes operações de renovação urbana, associadas à construção de infraestruturas ou empreendimentos imobiliários, que assentam na tábua rasa dos subúrbios afectados e estão muitas vezes associadas a violentos despejos forçados (bairros Iraque e Bagdad, 2009). São exemplos, realizados ou em curso, a intervenção na Nova Marginal Sul/Estrada do Samba e na Boavista, bem como os projectos residenciais Nova Vida e Talatona, este último seguindo o conceito do condomínio Alphaville de São Paulo. Também para Luanda Norte, como referido, foi elaborado um plano director de reconversão dos municípios de Rangel, Cazenga e Sambizanga, que aposta na renovação dos musseques, embora alguns técnicos angolanos insistam na necessidade de alargar o debate à comunidade local.

Em Maputo, nalguns bairros suburbanos estrategicamente localizados (virados para a baía ou junto 
a vias principais) observa-se um processo paulatino de renovação, conduzido por particulares, associados a projectos residenciais de luxo (Costa do Sol e Polana Caniço), ou a actividades económicas (Maxaquene). Noutros casos, a renovação é sancionada pelo Conselho Municipal, a partir da elaboração de um plano, na sequência da pressão dos promotores e investidores. É o caso de Maxaquene, alvo de um plano parcial de urbanização recentemente aprovado, que assenta na tábua rasa do tecido existente, segundo decisão do Conselho Municipal e contrariando a intenção inicial de qualificação, defendida pela equipa responsável pela sua elaboração (Universidade e ONGs espanhola e local). 0 mesmo acontece com a área da Praça de Touros, objecto de um plano ainda não aprovado, promovido por investidores privados.

\section{Expansão urbana mercantilizada}

Inclui-se nessas operações a construção, na periferia, de grandes infraestruturas de saneamento ou viárias, de grandes equipamentos colectivos ou comerciais e de conjuntos empresariais e residenciais para classes mais favorecidas. São exemplo, em Luanda, os projectos habitacionais promovidos pelo Estado, como a referida cidade do Kilamba (ver Figura 2A) e as Torres do Zango (construídas por empresas chinesas), no âmbito do programa Meu Sonho, Minha Casa, inacessíveis para a maioria da população. Em Maputo, é exemplo a nova centralidade do Zimpeto, com os complexos habitacionais da Vila Olímpica (de promoção pública e construção por empresa portuguesa) (ver Figura 2B), da Urbanização do Zimpeto (de promoção e construção por empresa portuguesa) e para funcionários municipais (promoção e construção chinesa). Notícias recentes publicadas na imprensa angolana e moçambicana dão conta de irregularidades na atribuição dos apartamentos.

\section{Reassentamento}

As acções de renovação e de expansão urbana mercantilizada estão muitas vezes associadas a processos de reassentamento dos habitantes dos territórios demolidos, geralmente, em áreas mais periféricas e distantes das oportunidades de emprego e dos principais equipamentos e serviços. Esses processos podem também resultar de outro tipo de situações: (1) valorização fundiária dos subúrbios com localização estratégica, levando à expulsão dos seus residentes (Chicala em Luanda); (2) situações de risco, de edifícios centrais sem condições de habitabilidade ou de áreas sujeitas à ocorrência de desastres naturais, geralmente associadas à valorização fundiária do terreno e levando ao desalojamento de populações (prédio da Cuca em Luanda); (3) calamidades naturais, de que foram exemplo as calemas da Ilha de Luanda e as cheias do bairro da Coreia, bem como as ocorridas em 1998 e 2000 em Maputo.

Embora os reassentamentos apresentem algumas semelhanças nas duas cidades, nomeadamente quanto à precariedade de infraestruturas básicas e de titulação de ocupação, identificam-se diferenças substanciais relacionadas com os procedimentos
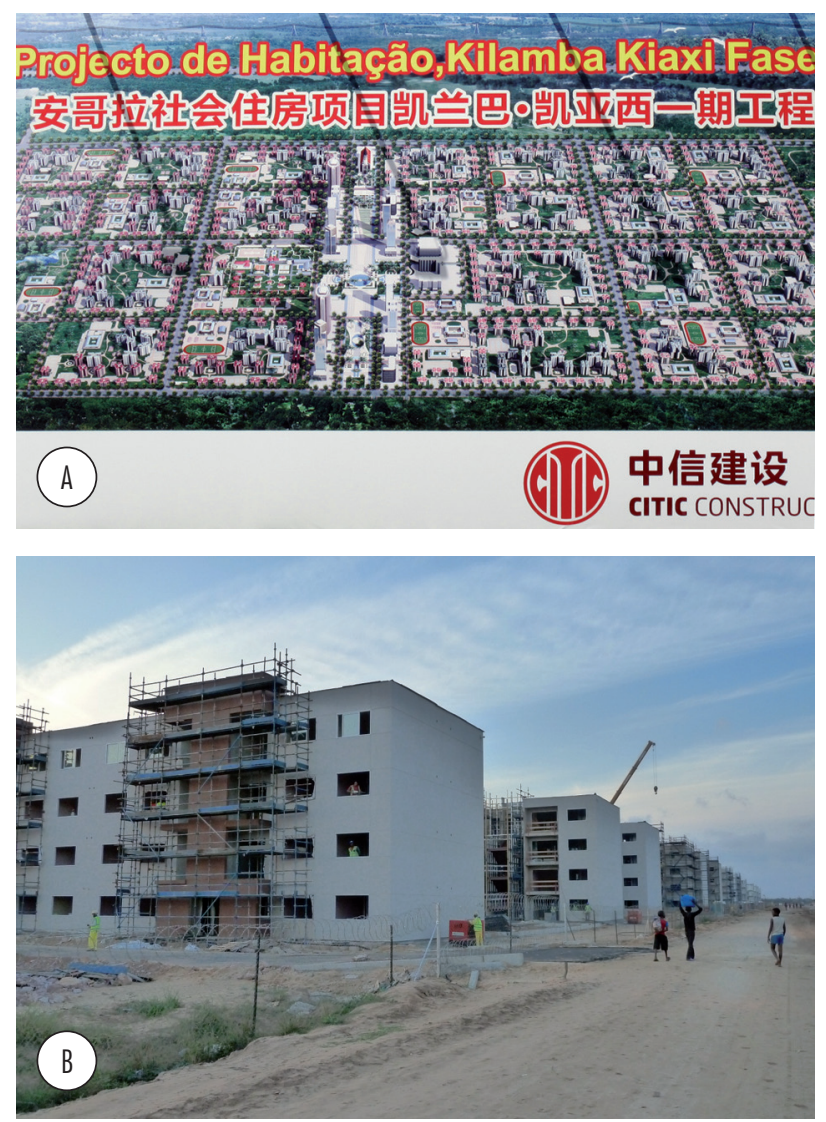

Figura 2 - Exemplos de expansão urbana mercantilizada em Luanda e Maputo

Legenda: 2A | Luanda - Nova Cidade Satélite do Kilamba Fonte: Silvia Viegas, 2012; 2B | Maputo - Vila Olímpica Fonte: Vanessa Melo, 2011 
mais autoritários de Luanda. Nesta cidade, os reassentamentos assumem carácter massivo e coercivo, limitando-se à disponibilização de um terreno para instalação provisória das populações, ou à atribuição de uma habitação (ao abrigo do programa Meu Sonho, Minha Casa), mas sem as condições mínimas de habitabilidade (Zango, Sapú e Panguila) (ver Figura 3A). Em Maputo, os reassentamentos desenvolvem-se sob coordenação municipal, por um conjunto alargado de organizações, existindo um Quadro de Política de Reassentamento, actualizado em 2010 no âmbito do ProMaputo. Na maioria das situações, houve atribuição de um talhão e/ou uma compensação monetária, verificando-se em menor escala a atribuição de habitações, como foi o caso em Magoanine C (ver Figura 3B),

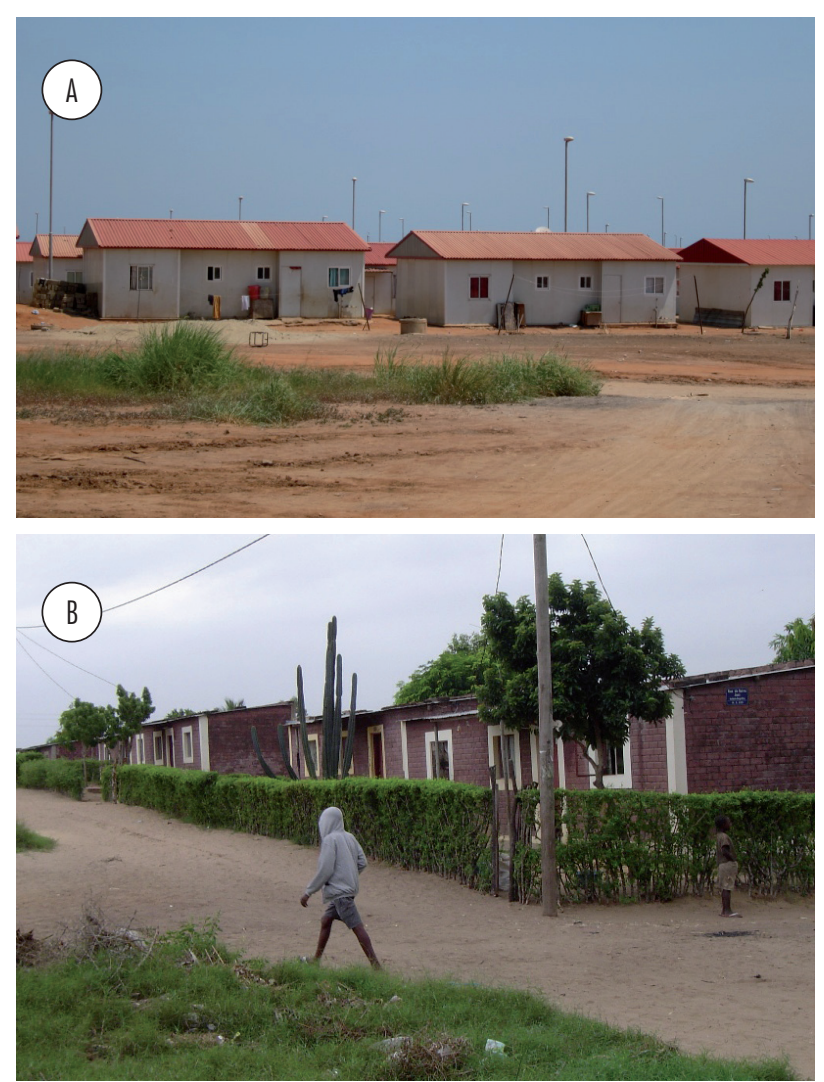

Figura 3 - Exemplos de reassentamentos em Luanda e Maputo Legenda: 3A | Reassentamento em Luanda - Panguila Fonte: Silvia Viegas, 2012; 3B | Reassentamento em Maputo - Magoanine C.

Fonte: Vanessa Melo, 2011. na sequência das cheias de 2000, tendo envolvido várias ONGs, e em Magoanine B, na qualificação da Estrada Nacional n. 4, com a participação da empresa CMC África Austral.

\section{Regularização fundiária}

As intervenções de renovação e extensão urbana e os reassentamentos têm subjacente o não reconhecimento da cidade autoproduzida, insistindo-se nas suas deficiências e desvalorizando o investimento dos seus habitantes-construtores, o que, como referem Groenewald et al. (2012) e Raposo (2012), condiciona os paradigmas de intervenção. Assim, apesar da Lei de Terras de ambos os países legitimar a ocupação costumeira da terra, as condições de atribuição de títulos de ocupação tornam difícil ou impossível sua obtenção pela maioria das populações dos subúrbios.

Em Luanda, alguns políticos e técnicos provinciais e municipais defendem o reconhecimento das ocupações dos subúrbios autoproduzidos, na sequência de operações de qualificação e renovação, conforme a visão oficial do governo central, que considera essas ocupações como ilegais e susceptíveis de demolição (DEVELOPMENT WORKSHOP, 2005) e condiciona ou impossibilita sua regularização fundiária. Em Maputo, as perspectivas locais são mais abertas ao reconhecimento da ocupação suburbana, embora as condições para a atribuição dos títulos de ocupação sejam muito difíceis de satisfazer nos subúrbios mais centrais, dada sua localização estratégica, sendo mais frequente na sequência de acções de qualificação (Chamanculo C). Em contraponto, nos subúrbios mais afastados do centro, assiste-se à aposta recente do Conselho Municipal, com apoio do BM, na sua regularização massiva, de que existem já alguns ensaios.

\section{Qualificação6 e participação}

O reconhecimento dos subúrbios autoproduzidos pode conduzir a outro tipo de práticas de

\footnotetext{
${ }^{6}$ Utiliza-se o conceito de qualificação na sua acepção de melhoramento do tecido existente em oposição à renovação ou "requalificação", tal como é utilizado nos dois países, e que assenta na tábua rasa do existente.
} 
carácter emancipatório, direccionadas para a qualificação e para o envolvimento dos habitantes nos projectos e/ou acções. Incluem-se nessa categoria um diversificado tipo de intervenções, sobretudo imateriais (educação e saúde, socioculturais, geração de rendimento, microcrédito, direitos humanos), mas também materiais (reabilitação ou construção de infraestruturas e equipamentos básicos). São principalmente intervenções pontuais, de pequena escala, muitas vezes de carácter mais paliativo que emancipatório, com investimento financeiro muito inferior ao das operações de renovação ou expansão urbana mercantilizada, conduzidas por organizações cívicas, ou por agências bi e multilaterais ou, em Maputo, pelo Conselho Municipal (RAPOSO; RIBEIRO, 2007). A capacidade de intervenção das ONGs nacionais é geralmente inferior à das internacionais, que dispõem de mais recursos, mas são poucas, nacionais ou internacionais, as que se destacam pelo seu desempenho nas áreas suburbanas (caso da AMDU moçambicana em Maputo e da Development Workshop em Luanda).

Como exemplo de intervenções de maior escala em Luanda, desenvolvidos pela DW, destacam-se: no início deste período (1987), o projecto-piloto de melhoramento do Sambizanga, assente numa estratégia participada de fornecimento e gestão de serviços urbanos básicos (DEVELOPMENT WORKSHOP, 2005); nos anos 90, o projecto de construção de 5 mil latrinas, visando a beneficiar 50 mil pessoas (RAPOSO, 2007); no novo milénio, o programa Monitoria Participativa da Pobreza (2012), centrado na construção de projectos para e com a comunidade, tais como chafarizes comunitários?

Em Maputo, como intervenções de pequena escala, são exemplo: nos anos 90, o programa Pfuka Dzixile e uma iniciativa municipal baseada no lema "comida pelo trabalho", envolvendo a população e algumas ONGs, em particular a moçambicana AMDU; no fim da primeira década do milénio, a intervenção de saneamento em Maxaquene A, efectuada por uma ONG espanhola (ESFC) em parceria com a ONG moçambicana AMDEC. Quanto a intervenções mais alargadas, salienta-se: em 1985 e em 1998, o Programa Nacional de Saneamento a Baixo
Custo, sedeado no INPF, financiado pelas Nações Unidas e outras agências, desenvolvido por um técnico sueco, para disseminação da latrina melhorada nos bairros periurbanos; em 2004, a intervenção em Mafalala para construção de fontanários, pavimentação de ruas principais e abertura de valas de drenagem, com o envolvimento da AMDEC; e, em 2005, o projecto participado de reordenamento do Chamanculo, iniciado a partir de um diagnóstico académico, uma experiência piloto de iniciativa municipal, contando actualmente com o apoio da Cities Alliance (cooperação Itália e Brasil). Em Maputo destaca-se ainda, a partir de 2008 e no âmbito do ProMaputo, o embrionário processo de orçamento participativo, a partir da experiência pioneira do Brasil, que visa a promover o debate público sobre a gestão dos recursos municipais.

\section{Apontamentos finais em torno da circulação de influências}

Até às independências, a transformação de Luanda e de Maputo estava vinculada às leis, normativas e práticas do poder político e técnico português, embora a maior distância ao poder ditatorial da "metrópole" tenha possibilitado a expressão de uma modernidade mais arrojada e a experimentação de novas ideias urbanísticas. A "geração africana" de arquitectos portugueses, influenciada por nomes como Le Corbusier ou Lúcio Costa, transferiu para as colónias as influências arquitectónicas e urbanísticas, europeias e internacionais.

As duas urbes eram também, nas vésperas das independências, palco de grandes transformações, fruto do assédio de grandes empresas portuguesas e estrangeiras, presenciando-se o início das actuais metamorfoses, assentes na demolição do património antigo e na verticalização. Em contrapartida, os subúrbios das duas cidades eram territórios marginais, excluídos e ignorados pelos políticos, pelos promotores e pela generalidade dos arquitectos-urbanistas modernos. As raras e virtuosas excepções espelhavam pressões internacionais, novas políticas coloniais "integradoras", ou novos ventos

\footnotetext{
7 Informação verbal prestada pela Development Workshop em entrevista cedida a Sílvia Viegas - uma das autoras deste artigo - e Rafael Pereira, em 7 de maio de 2012.
} 
emancipadores que haveriam de conduzir ao Abril de 1974 em Portugal e ao novo paradigma urbanístico que temporariamente configurou: interactivo, participado, diverso, flexível e transformador.

A utopia socialista que nasce com as independências, depois de uma longa gestação nas lutas armadas, apoiadas internacionalmente, apresenta-se como uma ruptura abrupta com as dinâmicas territoriais anteriores, em nome da equidade e inclusão dos subúrbios na cidade. Novos protagonistas vão conduzir e acompanhar esses novos desígnios: (1) os dirigentes políticos, com diferentes visões sobre o desenvolvimento urbano, desde o melhoramento e reordenamento do existente, os processos participados e a autoconstrução, até aos edifícios colectivos, aos processos top-down e à pré-fabricação; (2) os poucos arquitectos portugueses que se mantiveram nesses territórios e optaram pela nacionalidade dos novos países, enquanto actores da transformação urbana ensaiando intervenções inovadoras nos subúrbios, na habitação, no planeamento da cidade, no quadro da administração ou da Universidade pública; (3) os cooperantes portugueses apoiantes dessa utopia da construção de uma cidade socialista misturaram-se com cooperantes de outras nacionalidades; (4) os cooperantes do bloco socialista, da China, do Leste europeu, cubanos e soviéticos (esses dois últimos sobretudo em Luanda), integrando aí os serviços de habitação e de ordenamento do território, defendendo a construção em altura e prefabricada; (5) uma miríade de cooperantes do mundo ocidental, sobretudo em Maputo, na referida DNH/INPF, participaram em múltiplas discussões e experiências alternativas que incluíram a formação de quadros nacionais, uma das grandes "insuficiências" desse período em ambas as cidades.

A aposta na criação de uma cidade mais equitativa confrontou-se com inúmeras resistências e obstáculos, internos e externos, das guerras civis, às crises políticas, inerentes às mudanças radicais implementadas, às medidas autoritárias e repressivas, às crises económicas, às calamidades tropicais, à falta de recursos, de informação, de formação. O esforço no ordenamento dos subúrbios, mais relevante em Maputo, foi insuficiente em face de seu crescimento acelerado com o grande afluxo de rurais e deslocados de guerra. Em meados dos anos 80, a dualidade colonial em cada uma das cidades tinha sido esbatida, com a degradação das zonas urbanizadas - em parte ocupadas desde as nacionalizações por habitantes suburbanos ou novos citadinos - e com o melhoramento dos subúrbios.

A crise económica, a guerra e o desmoronamento do bloco socialista conduzem ambos os países a uma nova ruptura marcada pela abertura à economia de mercado e a um sistema multipartidário que ditam a emergência de um capitalismo neoliberal e o agravamento das desigualdades socioespaciais. Essa inflexão assume contornos diferentes nos dois países. Em Angola, a exploração do petróleo abriu o país à entrada massiva do capital internacional, mas permitiu maior independência das instituições de Bretton Woods. Em contrapartida, são essas que, em Moçambique, ditaram as reformas económico-financeiras e políticas. Com o multipartidarismo e as novas Leis de Associações nos dois países, novos actores emergem nas duas cidades, para além do governo central, submetido em Angola ao poder presidencial, que vão influenciar, de formas distintas nas duas cidades, planos e práticas urbanas: investidores privados, organizações internacionais multi e bilaterais, governo municipal e organizações cívicas.

As duas cidades-metrópole inscritas na lógica de competitividade e internacionalização do capital têm privilegiado o investimento privado nacional e transnacional para operar sua modernização, renovação e expansão urbana. Fervilham empresas de construção de várias nacionalidades, predominantemente chinesas, portuguesas, brasileiras, israelitas, muitas vezes internacionalizadas, com parcerias entre si e/ou com empresas nacionais públicas e privadas, com financiamento próprio, dos seus governos ou de empréstimos bancários. Retoma-se a dinâmica destruidora e renovadora que se afirmava nas vésperas das independências. Constroem-se grandes infraestruturas e projectos imobiliários, obras públicas, equipamentos, conjuntos residenciais, para as classes médias e altas das áreas urbanizadas, marcados por grande investimento tecnológico e dispêndio de recursos, sem respeito pelo lugar nem pelo património, sem preocupação de sustentabilidade ambiental, urbanística, económica ou sociocultural. Arranha-céus ao "estilo Dubai" reproduzem-se em Luanda e emergem em Maputo, numa perspectiva de marketing urbano a simbolizar a economia neoliberal em alta, com a exploração de recursos naturais (petróleo, carvão e gás natural). 
Essas cidades competitivas e vorazes expulsam para suas margens os subúrbios autoproduzidos, que se densificam, diferenciam e estendem para periferias cada vez mais longínquas, alguns muito depauperados ou arrasados pela natureza e pelo capital. No caso de Luanda, o poder político, forte e centralizado, faz tábua rasa do tecido construído estrategicamente localizado. A cidade dual regressa mais desigual e agressiva.

A exploração do petróleo em Angola permitiu sua independência em relação às agências internacionais e a suas condições de ajuda, enquanto em Moçambique, especificamente o BM e as nações Unidas, tornam-se condutoras da reforma da administração pública e do processo de descentralização e municipalização ainda por implementar em Luanda. A criação do município de Maputo, nos anos 90, estimulou o debate sobre a cidade no seio de uma sociedade civil dinâmica que perderá peso ante a crescente mercantilização da cidade e a submissão do poder municipal aos interesses do capital.

Também nos anos 90, no quadro da lógica de "menos e melhor Estado", as Nações Unidas advogam a transferência para as ONGs de algumas competências da administração pública, embora posteriormente defendam o fortalecimento institucional e, mais recentemente, no caso de Maputo, a prioridade à intervenção nos subúrbios. Em todo o caso, nas duas cidades, assiste-se à entrada na cena (sub)urbana de novos actores, ONGs, congregações religiosas, organizações comunitárias de base e universidade (particularmente interventiva em Maputo).

Os diferentes contextos económicos, militares e institucionais desde os anos 90 explicam um sistema de planeamento distinto nas duas cidades: menos estruturado e tendencialmente top-down, em Luanda, com controle presidencial e desenho de empresas estrangeiras, entre as quais algumas portuguesas em parceria e uma libanesa muito próxima da presidência; em Maputo, a escola de planeamento físico forjada desde o período da utopia socialista cria um corpo profissional moçambicano defensor do ordenamento do território e autor da maioria dos planos, com financiamento de agências multi e bilaterais (BM, ONU, Cities Alliance, Brasil, Itália) e com discussão por uma sociedade civil organizada. Ambos os países são influenciados nos últimos anos pela legislação urbanística portuguesa.

Ao nível dos paradigmas suburbanísticos, as intervenções situam-se entre: (1) uma abordagem de tipo neoliberal em que o espaço se reconfigura segundo a lógica do capital e engloba operações de renovação e expansão urbana mercantilizada, promovidas por privados e/ou pelo poder público, ligadas a processos de periferização e reassentamentos dos grupos sociais de menores recursos, mais excludentes em Luanda, onde ocorrem despejos forçados denunciados e combatidos por ONG nacionais (como SOS Habitat); (2) uma abordagem mais emancipadora voltada para a qualificação dos tecidos autoproduzidos, maioritariamente conduzida por organizações cívicas, em Maputo, também pelo governo municipal, em acções de maior vulto, e considerando o envolvimento dos residentes. Próximo dessa óptica há a referir duas medidas esboçadas em Maputo pelo BM, direccionadas para os municípios e baseadas em experiências precursoras no Peru e no Brasil: a regularização fundiária e o orçamento participativo. Elas são inexistentes em Luanda, o que reforça a diferença entre o tipo de intervenções suburbanas recentes nas duas cidades.

Diante da contínua extensão territorial dos subúrbios e de sua crescente complexidade, essas acções por mais emancipadoras que sejam revelam-se sempre insuficientes. Os subúrbios suburbanizados são expressão da desigualdade socioeconómica, que grassam nessas sociedades capitalistas, particularmente contrastante em Luanda, e se acentuam com os grandes projectos insustentáveis de acumulação de capital que competem nas áreas urbanizadas. Nas suas margens crescem os territórios "outros", autoproduzidos, não oficiais, ditos informais, que se reproduzem segundo regras próprias emanadas do corpo social que lhes dá forma. Seus residentes continuam a ser os principais arquitectos da sua transfiguração. No meio da miríade dos novos actores que hoje encenam nesses territórios, quais são portadores de mudança? Até que ponto o reforço das relações no espaço lusófono ou lusófilo pode constituir uma mais valia para uma nova inflexão emancipadora?

\section{Referências}

AMARAL, I. Apontamentos sobre Luanda: uma capital colonial imperfeita. UR Cadernos da Faculdade de Arquitectura da Universidade Técnica de Lisboa: Cidades Africanas, n. 5, p. 48-56, maio. 2005. 
ANGOLA. Lei das Associações (1991). Lei n. 14/91. Diário da República. Luanda, 1991.

ANGOLA. Lei do Ordenamento do Território e do Urbanismo (2004). Lei n. 3/2004. Diário da República. Luanda, 2004a.

ANGOLA. Lei de Terras (2004). Lei n. 9/2004. Diário da República. Luanda, 2004b.

CROESE, S. 1 million houses?: Angola's national reconstruction and Chinese and Brazilian engagement. Strengthening the civil society perspective - Series II: China and other emerging powers in Africa. Cape Town: Emerging Powers in Africa Initiative. Fahamu, 2011. Disponível em: <http://www.fahamu.org/images/empowers_report_0311.pdf>. Acesso em: 5 nov. 2011.

DEVELOPMENT WORKSHOP- DW. Terra: reforma sobre a terra urbana em Angola no período pós-guerra - pesquisa, advocacia e políticas de desenvolvimento. Luanda: DW, CMAAH, 2005.

FAURÉ, Y-A. Angola e Moçambique: de uma descentralização prometida a uma descentralização tímida. In FAURÉ, Y.; RODRIGUES, C. (Org.). Descentralização e desenvolvimento local em Angola e Moçambique: processos, terrenos e atores. Coimbra: Almedina, 2011. p. 295-354.

FERNANDES, J. M. Geração Africana. Arquitectura e cidades em Angola e Moçambique. 1925-1975. Lisboa: Livros Horizonte, 2002.

FORJAZ, J. Uma estratégia para o melhoramento e a reabilitação dos slums em Moçambique. Ur Cadernos da Faculdade de Arquitectura da Universidade Técnica de Lisboa: Cidades Africanas, n. 5, p. 92-97, maio 2005.

FORJAZ, J. (Coord.). Moçambique, melhoramento dos assentamentos informais: análise da situação e proposta de estratégias de intervenção. Maputo: Direcção Nacional de Planeamento e Ordenamento Territorial (DINAPOT); Ministério para a Coordenação da Acção Ambiental (MICOA), 2006. Disponível em: <http://www. unhabitat.org/downloads/docs/4399_50963_CWS\%20 in\%20portuguese.pdf>. Acesso em: 20 out. 2012.

GROENEWALD, L.; HUCHZERMEYER, M.; KORNIENKO, K. et al. Breaking down the binary: meanings of informal settlement in southern african cities. In: FOURCHARD, L.; BEKKET, S. Governing african cities. South Africa: HSRC Press, 2012. No prelo.
HARVEY, D. The right to the city. 2008. Disponível em: <http://187.45.205.122/Portals/0/Docs/righttothecity.pdf>. Acesso em: 4 mar. 2012.

HARVEY, D. Spaces of capital: towards a critical geography. New York: Routledge, 2001.

JORGE, S.; MELO, V. Processos e dinâmicas de (re)produção do espaço (peri)urbano: o caso de Maputo. In: CONGRESSO INTERNACIONAL DE JOVENS INVESTIGADORES URBANOS (SICYUrb), 2., 2012, Lisboa. Actas... Lisboa: SICYUrb, 2012. Disponível em: <http://conferencias. cies.iscte.pt/ index.php/icyurb/sicyurb/paper/viewFile/105/128>. Acesso em: 3 maio 2012.

LEFEBVRE, H. La production de l'espace. Paris: Anthropos, 1974.

LOPES, C. M.; AMADO, F.; MUANAMOHA, R. Dinâmica do crescimento populacional em Luanda e Maputo. In: OPPENHEIMER, J.; RAPOSO, I. (Coord.). Subúrbios Luanda e Maputo. Lisboa: Edições Colibri, 2007. p. 37-64.

MARTINS, M. I. A evolução de Luanda e o fenómeno da globalização. Ur Cadernos da Faculdade de Arquitectura da Universidade Técnica de Lisboa: Cidades Africanas, n. 5, p. 57-61, maio 2005.

MELO, V. Urbanization processes in the expansion areas of Luanda, Maputo and Johannesburg: urban planning and everyday practices. In: INTERNATIONAL PLANNING HISTORY SOCIETY (IPHS) CONFERENCE, 15., 2012, São Paulo. Actas... São Paulo: FAUUSP, 2012.

MOÇAMBIQUE. Lei das Associações (1991). Lei n. 8/91. Diário da República. Maputo, 1991.

MOÇAMBIQUE. Lei de Terras (1997). Decreto-lei n. 19/1997. Diário da República. Maputo, 1997.

MOÇAMBIQUE. Lei do Ordenamento do Território (2007). Lei n. 19/2007. Diário da República. Maputo, 2007.

OPPENHEIMER, J.; RAPOSO, I. A pobreza em Maputo. Lisboa: MTS, 2002.

OPPENHEIMER, J.; RAPOSO, I. (Coord.). Subúrbios de Luanda e Maputo. Lisboa: Edições Colibri, 2007.

RAPOSO, I. Instrumentos e práticas de planeamento e gestão dos bairros peri-urbanos de Luanda e Maputo. In: OPPENHEIMER, J.; RAPOSO, I. (Coord.). Subúrbios Luanda e Maputo. Lisboa: Edições Colibri, 2007. p. 219-246. 
RAPOSO, I. Sinais de modernidade na arquitectura popular em Luanda. In: GOYCOOLEA PRADO, R.; Martins, I. M. (Dir). A modernidade ignorada. Arquitectura moderna de Luanda. Madrid: Universidad de Alcalá, 2011. p. 172-189.

RAPOSO, I. Bairros de génese ilegal: metamorfoses dos modelos de intervenção. In: MENDES, M. M.; Ferreira, C., SÁ, T.; CRESPO, J. L. (Coord.). A cidade entre bairros. Lisboa: Caleidoscópio, 2012. p. 107-119.

RAPOSO, I.; RIBEIRO, M. As ONG, um novo actor do desenvolvimento urbano em Luanda e Maputo. In: OPPENHEIMER, J.; RAPOSO, I. (Coord.). Subúrbios Luanda e Maputo. Lisboa: Edições Colibri, 2007. p. 175-218.

RAPOSO, I.; SALVADOR, C. Há diferença: ali é cidade, aqui é subúrbio: urbanidade dos bairros, tipos e estratégias de habitação em Luanda e Maputo. In: OPPENHEIMER, J.; RAPOSO, I. (Coord.). Subúrbios Luanda e Maputo. Lisboa: Edições Colibri, 2007. p. 105-138.

UN-HABITAT. Mozambique Urban Sector Profile. Naoirobi: UN, 2008. Disponível em: <http://www.urbangateway.org/sites/default/ugfiles/MozambiqueUSP\%202008.pdf>. Acesso em: 7 nov. 2008.
UN-HABITAT. The state of african cities 2010: governance, inequality and urban land markets. Nairobi: UNHABITAT, 2010. Disponível em: <http://www.unhabitat. org/documents/SACR-ALL-10-FINAL.pdf>. Acesso em: 13 jan. 2011.

VALENÇA, M. Cidades Ingovernáveis? Ensaio sobre o pensamento harveyano acerca da urbanização do capital. In: BORZACCHIELLO DA SILVA, J.; CRUZ LIMA, L. C.; DENISE, E. (Org.). Panorama da geografia brasileira. São Paulo: Annablume, 2006.

VIEGAS, S. Urbanization in Luanda: geopolitical framework. A socio-territorial analysis. In: INTERNATIONAL PLANNING HISTORY SOCIETY (IPHS) CONFERENCE, 15., 2012, São Paulo. Actas... São Paulo: FAUUSP, 2012.

Recebido: 31/05/2012

Received: 05/31/2012

Aprovado: 25/10/2012

Approved: $10 / 25 / 2012$ 